Session 2793

\title{
Capstone Design Projects in Undergraduate Electrical Engineering Education
}

\author{
E. H. Shaban \\ Electrical Engineering Department \\ Southern University \\ Email: eshaban@ clsuter.engr.subr.edu
}

Integrating design in an undergraduate electrical engineering curriculum and the application of creative design ideas in senior capstone design projects have received ample comments from repetitive ABET visitor's teams. To address such a serious deficiency that is critical to the program survival, a radical change must be established to rectify it. We suggest to make changes in syllabi contents, stress design in courses and exams, select and retain oriented engineering faculty, show cases in courses, examinations, and laboratories that assist the students to practice design. This paper outlines suggestions and recommendations that may substantially improve the capstone design in undergraduate electrical engineering to satisfy the rigorous challenge of ABET requirements.

\section{Introduction}

The Accreditation Board for Engineering and Technology (ABET) is a private professional agency responsible for peer review of engineering programs to meet minimum standards set forth by the agency and to enhance the existing and develop future educational programs. Accredited programs provide the public, prospective students, student counselors, parents, educational institutions, professional societies, potential employers, governmental agencies, and state boards of examiners, specific programs that meet minimum criteria for accreditation. ABET criteria/2000 assess the programs with respect to: students, program educational objectives, program outcomes and assessment, professional component, faculty, facilities, institutional support, and financial resources [1].

The engineering graduate should be able to apply the knowledge of mathematics, science, and engineering to analyze, formulate, interpret data, and design practical engineering working systems. The engineering program should train the student for a life long learning, to work professionally and ethically in multi-disciplinary teams, to communicate orally, and in writing concerning technical documentation [2-4].

The professional component requirements specify subject areas appropriate to engineering but do not prescribe specific courses. Students must be prepared for engineering practice through the curriculum culminating in a major design experience based on the knowledge and the skills acquired in earlier courses. The design experience 
should incorporate engineering standards and realistic constraints that include most of the following factors: economic; environmental; ethical; health and safety; social; political, sustainability; and manufacturability of the designed product [1].

Engineering employers expect the engineering graduates to be able to engage in engineering practice as soon as they graduate or within a short time following graduation. The university must therefore train and prepare the students to engage in projects and experiences that are similar to what the graduates will encounter in the workplace [5-7]. Employers have been offering summer jobs and co-op opportunities to engineering students before they graduate in order to allow the prospective engineering graduates to become familiar and work with engineering teams on practical projects. The capstone design project is a culmination of sequence of engineering courses, experimental laboratories, summer jobs, co-op experience, team work, planning, oral and written communication, applications of engineering standards, recognition of the contribution of others, respect to the environment, and the impact on the local economy. The majority of these objectives cannot be taught in a single course in the curriculum. ABET requires that the graduates and the capstone design should be able to demonstrate all of the above objectives. The objectives and outcomes of the capstone design should be assessed and measured by the instructor and the results must be demonstrated to improve the content and methods of teaching in the curriculum. This paper suggests how to improve the curriculum and the students' learning to achieve acceptable outcomes in the capstone design in electrical engineering.

Southern University has an undergraduate electrical engineering program. The faculty has very limited specializations with terminal degrees in electrical engineering. There are two faculty members in power systems, and at least two faculty members who have terminal degrees in physics and physical chemistry. This has not been helpful to enrich the students with a broad specializations in electrical engineering design projects. It is required that the students enroll in introductory courses such as controls and communications. The courses have analysis and design components and it is up to the instructor whether or not to assign a design project. In addition, there are elective courses that are rarely offered because of low enrolment. The elective courses in the catalog are divided into computer engineering, controls and power systems, communications, and electronics. The computer group includes computer architecture, digital systems, operating systems, computer networking, and computer networking laboratory. There are no faculty members who are specialized in computer engineering. Computer engineering core and elective courses are taught by non specialized faculty. Controls and power systems include: discrete control systems, control systems laboratory, optimization techniques, network synthesis, electrical machines, and power systems analysis. The communication group includes electromagnetic field theory and laboratory, communication engineering, communication systems laboratory, microwaves, computer communication systems. The electronic group includes theory and fabrication of solidstate devices, integrated circuit design and analysis, mechatronics, advanced topics in electrical engineering, and electrical design laboratory. 
The elective courses are offered during the senior year at the same time that the capstone design course is offered. Usually, the students enroll in both the design course and the elective courses in the senior year. The knowledge and depth of the elective courses will definitely enhance the successful completion of the design projects.

During the first semester of the senior year, the students are given general ideas of how to search for and select a design project. Teams are assigned, and the project definition, its goals, planning, and documentation are drafted. Each team should have a chair and a recorder. The advisor must meet with the teams in a weekly basis to monitor their progress. The team chair should divide the project into small modules assigned to each member of the team and provide strict deadlines to finish the assignments. A flow diagram, simulation programs, theoretical analysis, and all successes and failures must be documented. In the second semester the student should be able to assemble their project and test it.

The students and the instructor should bear in mind the criteria that ABET has stressed in the final design project such as engineering standard codes, ethical engineering decisions, respect to safety, and avoidance of the use of hazardous material. The design project should provide solutions to social problems, the impact of the project in the local and global economy, teamwork, and application of previous knowledge in the curriculum.

Probably the most difficult part is to find suitable projects, with practical applications, of relatively equal level of difficulty that can be accomplished within two semesters. It is proposed that the local industry in collaboration with the university should select an advisory board to provide a pool of practical projects in a design clinic. The students also should form a committee that can propose projects that are of practical interest with the approval of the instructor to be added to the design clinic. The second step is how to distribute the projects among the students and how to select the teams that have both interest in the project and are willing to work with one another professionally [3].

\section{Design in the Curriculum}

To embark in a radical change, to incorporate real world design problems in the curriculum, requires an assessment of the current portion of design in various courses. A new and innovative approach must be implemented to reflect the applications of real world design problems in both core and elective courses. This effort calls for the participation of both the faculty and many industrial partners. New and enhanced technological tools and software must be used and practiced by the students to facilitate descriptive design ideas and proof of concepts for real world design examples. More examples in the sophomore and the junior years must include good design problems that reflect successful practical designs that have been accomplished or are in progress in the industry. The curriculum breadth and depth in the engineering program must span the state of the art of the engineering achievements. Design by its nature requires innovation for an open ended, complex, and multi-disciplinary problems. The recent software versions of high level languages such as Verilog and VHDL must be made available and the students must be encouraged to use the software to perform their homework, design 
projects, and laboratories [8]. This effort requires a dedicated and qualified faculty together with enthusiastic and hard working students. Unfortunately, both factors have not been fully addressed in the electrical engineering program at Southern University. A senior faculty advisor should co-ordinate the design courses across the curriculum with the help and assistance of the faculty across the engineering disciplines. In add ition, the selection and admission of outstanding students and the retention of competent faculty members are highly recommended to fulfill the stated objectives of the engineering program and the university mission.

Precursor courses, laboratories, and the state of the art software must be offered to the students prior to undertaking the capstone design. This experience will equip the students with the necessary technical and non-technical skills that are necessary for successful completion of the capstone design course. The design course usually spans two semesters from inception, to sound conceptual design, to a working product. The student's teams must seek and persuade an industrial sponsor, a partnership, or an entrepreneur to finance the project. There are national design competitions that offer financial rewards for innovative and creative designs in engineering that the students can pursue.

The student's teams in the second course of the design course may perform as mentors and consultants to the student's teams in the first course. This can allow a more open discussion between the students and will enhance collaboration and teamwork. The students can use the entire engineering faculty members as mentors and consultants in addition to the industry volunteers and collaborators. Sometimes informal student's and faculty discussion can provide insight and novel ideas that can advance the design projects.

\section{Assessment Criteria and Feedback}

Each design team must provide a clear project definition with objectives, constraints, specifications, and customer's expectations. A comprehensive documentation including the type and the number of components, the cost, and the different prototypes that are made should be recorded and provided to the advisor of the project in a weekly basis. The instructor should assess and document the progress of the team and the contribution made by each member of the team $[10,11]$. This will help the instructor to provide a fair grade for each member of the group at the end of the semester.

It is preferable to simulate the project using a schematic capture CAD (for example PSICE) or to write a descriptive program for the project using VHDL or Verilog languages. In general, the project does not work the first time, and therefore time must be made to debug and rerun the simulation or the prototype experiment repeatedly until an acceptable result is obtained.

The intent of the design project is innovation and creativity preferably different from what has already been achieved elsewhere. Repetition of work that has been accomplished is not acceptable unless new modifications have been made to make the 
same product works faster, lasts longer, or costs less. The students should be made aware in advance about the importance of this fact for an open-ended capstone design.

At the end of the semester, the students should present their work and accomplishment in an open and public session. During the project presentation the students can demonstrate how the preparatory courses in the sophomore, junior, and senior years have contributed to accomplish their senior project. Technical and non-technical problems that the students have encountered must be discussed and how they are able to overcome them. This will provide assistance for the forthcoming design groups. An exit survey must be conducted from the graduating students. A follow up survey must be conducted three years after graduation to the same groups. This survey will provide feedback of how the senior design has contributed to their success as practicing engineers. Faculty members who exert a remarkable effort in senior capstone design must be properly rewarded and compensated for their efforts.

NSF Synthesis Coalition has provided suggestions for student's outcomes assessment of goals based on abilities, activities, criteria, methods, measures, feedback, and evaluations. It is the instructor's responsibility to make a fair evaluation based on the above guidelines $[10,11]$. The instructor can test the student's ability by reviewing the student's activities such as progress portfolio, examining each module developed, and the assembled prototype as a simulated project. He can arrange for peer discussion among the teams, and allow the students to demonstrate and explain the operation of their project in a presentation to evaluate the communication skills [9]. The instructor should be able to propose and apply a method by which he can measure the activities that the students have performed. This requires a lot of experience so that the instructor can measure and rate the student's performance with a letter grade at the end of the semester. The instructor should provide a feedback to each student and team about their progress rate and provide suggestions how they can improve their performance in the project. Design course deficiencies that are discovered must be made public to the faculty and suggestions can be made to enhance the curriculum to address the deficiencies.

\section{Summary and Conclusion}

The intent of an engineering education and the capstone design project is to provide the graduate with the ability to perform practical life-long engineering missions in collaboration with multi-disciplinary teams in the industry following graduation. The industry must continuously feedback to the university the engineering problems that they encounter looking for solutions from the universities and the graduates. The project assessment results of the capstone design projects should be used to improve the curriculum and the design course to ensure that the students are aware of design at an early stage of the curriculum. Constraints in design that are not usually part of the engineering courses must be taught to the students. These factors may include: manufacturability and reliability of the project, the effect on the economy, the effect on health and safety, the environment, and the ethical conduct. The electrical engineering program at Southern University has undergone some changes with respect to the senior design course to meet ABET recommendations. Some of the above ideas and 
suggestions have been made available to the faculty in the electrical engineering program.

We would like to thank all the reviewers and Dr. Wils Cooley of West Virginia University for their suggestions and helpful comments that have improved the paper.

\section{References}

1. Http://www.abet.org

2. E. L. Wang, J. A. Kleppe, "Teaching Invention, Innovation, and Entrepreneurship in Engineering,” Journal of Eng. Ed., Vol. 90, 565, October, 2001.

3. T. L. Chambers, A. D. manning, L. J. Theriot, "A New Theory for the Assignment of Members of Engineering Design Teams," ASEE/GSW, TA\&M, College Station, TX, April 2001.

4. E. Koehn, "Educational Criteria for Engineering Design and Practice," ASEE/GSW, University of New Orleans, New Orleans, LA April 1998.

5. R. L. Huston, S. Anand, G. E. Seldman, "University Industry Design Clinic- A Decade of Experience With An Innovative Capstone Design Course," Intertech International Conference, University of Cincinnati, Cincinnati, OH June 2000.

6. Savant, Roden, and Carpenter, "Electronic Design," Bemjamin/Cummings Publishing company, Second edition, 1991.

7. J. A. Caton, R. Chona, and M. McDermott, "Achieving the Objectives of a Two-Semester Senior Design Sequence in Mechanical Engineering: Faculty Goals and Student Perception," ASEE/GSW, University of New Orleans, New Orleans, LA April 1998.

8. S. R. Eisenbarth, "Introducing Top-Down Design Principles in an Undergraduate Computer Systems Design Course," ASEE/GSW, University of New Orleans, New Orleans, LA, April 1998.

9. B. H. Swaile, "Professional Ethics and Critical thinking- A case Study Approach," Intertech International Conference, University of Cincinnati, Cincinnati, OH June 2000.

10. James E. Cross and A. Singh, "How to Configure and Assess Engineering Capstone Design Course,", ASEE/GSW, University of New Orleans, New Orleans, LA April 1998.

11. H. P. Mohamadian, S. I. Ibekwe, and C. L. Burris, "Implementation of Academic Assessment in Engineering Capstone Design,” ASEE/GSW, New Mexico State University, Las Cruces, NM March 2000.

\section{E. H. SHABAN}

Dr. Shaban is an associate professor in the Electrical Engineering Department, Southern University, Baton Rouge, LA. He attained the BSEE and MSEE in 1968, and 1978 from the University of Khartoum, Sudan, and the Ph.D. from the University of Florida, Gainesville, FL in 1986. He worked as a visiting professor at the University of Puerto-Rico, Mayguez in 1987-88, after which he joined Southern University, Baton Rouge, LA. 